\title{
The neurobiology of subjective tolerability to antipsychotic medications in Schizophrenia - is it also relevant to the genesis of comorbid addiction?
}

\author{
George Awad
}

\author{
From $1^{\text {st }}$ International Congress on Neurobiology and Clinical Psychopharmacology and European \\ Psychiatric Association Conference on Treatment Guidance \\ Thessaloniki, Greece. 19-22 November 2009
}

One of the frequent but unrecognized side-effects of antipsychotic medications is the subtle alterations in subjective tolerability to these medications, including feelings of anxiety, distress and lack of pleasure, and which often lead to dislike and aversion to medications, with known serious clinical consequences. Yet, those very patients take to frequent abuse of illicit drugs.

One popular and frequently accepted explanation for such a high association has been the self-medication hypothesis, which proved inadequate to explain all aspects of this phenomenon. Until recently, the neurobiological basis for alteration in subjective tolerability and the negative dysphoric responses to antipsychotic medications has not been clear, though it was generally understood that somehow it relates to dopamine, since all antipsychotic medications have antidopaminergic properties. In a series of studies, including our recent experimental dopamine depletion SPECT study, we demonstrated for the first time the relationship between negative subjective tolerability and dopamine-binding ratio in the nigro-striatal area. Our findings explain to a large part why only some patients, not all receiving antipsychotic medications, experience dysphoric responses, since only those who have low baseline dopamine function are more susceptible to further dopamine-blocking effects.

Meanwhile, emerging evidence from research in the addiction field has implicated dopamine in the same neural circuitry in motivational and reinforcement behaviour, which is central to initiation and continuation of

University of Toronto, Humber River Regional Hospital, Toronto, Canada dependency states. It's plausible, then, that what links vulnerability to addictions and negative subjective tolerability lies in a dysregulated dopamine signaling in the nucleus acumbens, resulting from frontal cortical and hippocampal dysfunction. Such a proposal, though many aspects of it have not yet been worked out clearly, and if confirmed represents a new rethinking of the concept of schizophrenia and its varied domains and manifestations and also has clinical implications in management.

Published: 22 April 2010

doi:10.1186/1744-859X-9-S1-S61

Cite this article as: Awad: The neurobiology of subjective tolerability to antipsychotic medications in Schizophrenia - is it also relevant to the genesis of comorbid addiction?. Annals of General Psychiatry 2010 9(Suppl 1):S61.

Submit your next manuscript to BioMed Central and take full advantage of:

- Convenient online submission

- Thorough peer review

- No space constraints or color figure charges

- Immediate publication on acceptance

- Inclusion in PubMed, CAS, Scopus and Google Scholar

- Research which is freely available for redistribution

Submit your manuscript at www.biomedcentral.com/submit

Biomed Central 